\title{
Rancang Bangun Aplikasi Sistem Inventory dengan Barcode di Laboratorium Teknik Elektro Universitas Bangka Belitung
}

\author{
Asmar $^{1}$, Ghiri Basuki Putra ${ }^{2}$ \\ Jurusan Teknik Elektro, Fakultas Teknik, Universitas Bangka Belitung ${ }^{1}$ \\ Jurusan Teknik Elektro, Fakultas Teknik, Universitas Bangka Belitung ${ }^{2}$ \\ *asmar@ubb.ac.id', ghiri-basuki@ubb.ac.id²
}

\begin{abstract}
The laboratory is a place for students to carry out practicum activities to better understand a subject. In the UBB Electrical Engineering laboratory, a lot of electronic tools and components are used so that an inventory of the equipment and components is needed so that they are easy to use. Previously, the inventory of goods at the Electrical Engineering Laboratory used a manual recording system so that its implementation was not running optimally and was still manual so that many problems occurred. To overcome this, an application is needed that is able to record equipment and components in the laboratory, the borrowing process, returns and the condition of existing goods automatically. This inventory application is made through several stages, namely, problem identification, design, application development and tool barcobe and application implementation stage. The application is made using data processing software, while the barcode is made using Barcode Studio. The results of this study have been applied to the Electrical Engineering Laboratory and are very helpful in the process of borrowing, returning, controlling the condition of existing goods in the laboratory, and making reports and can be done digitally and data storage becomes safer and electronic.
\end{abstract}

Keywords: Inventory, Barcode, Application

\section{INTISARI}

Laboratorium merupakan tempat mahasiswa melakukan aktifitas praktikum dalam lebih memahami suatu mata kuliah. Di laboratorium Teknik Elektro UBB banyak sekali alat dan komponen elektronika yang digunakan sehingga dibutuhkan invetarisasi peralatan dan komponen tersebut agar mudah dalam penggunaannya. Kegiatan inventaris barang pada laboratorium Teknik Elektro sebelumnya menggunakan sistem pencatatan manual sehingga dalam pelaksanaannya belum berjalan secara optimal dan masih manual sehingga banyak permasalahan yang terjadi. Untuk mengatasi hal tersebut diperlukan suatu aplikasi yang mampu mendata peralatan dan komponen yang ada di laboratorium, proses peminjaman, pengembalian dan kondisi barang yang ada secara otomatis. Aplikasi invetarisasi ini dibuat melalui beberapa tahap yaitu, identifikasi permasalahan, perancangan, pembuatan aplikasi dan barcode alat dan tahap implementasi aplikasi. Aplikasi dibuat menggunakan menggunakan software pengolah data, sedangkan barcode dibuat dengan Barcode Studio. Hasil dari penelitian ini telah diterapkan pada laboratorium Teknik Elektro dan sangat membantu dalam proses peminjaman, pengembalian, pengontrolan kondisi barang yang ada di laboratorium, dan pembuatan laporan dan dapat dilakukan secara digital serta penyimpanan data menjadi lebih aman dan elektronik.

Kata kunci: Inventaris, Barcode, Aplikasi

\section{PENDAHULUAN}

Laboratorium merupakan tempat mahasiswa beraktivitas dalam melakukan praktikum dan juga penelitian. Di laboratorium juga terdapat banyak peralatan dan komponen yang perlu dicatat agar tidak terjadi kehilangan dan lainnya. Dengan semakin meningkatnya kegiatan yang ada di laboratorium
Teknik Elektro Fakultas Teknik Universitas Bangka Belitung maka kebutuhan kertas dan waktu proses peminjaman alat dan bahan untuk praktikum maupun penelitian makin meningkat sehingga sangat menyulitkan apabila masih dilakukan secara manual karena akan membutuhkan waktu yang cukup lama. Untuk mengatasi hal tersebut diperlukan sistem yang 
bisa mengurangi penggunaan kertas dan proses peminjaman alat dan bahan yang tidak terlalu lama. Untuk mengatasi hal tersebut diperlukan suatu aplikasi yang mampu mendata peminjaman, pengembalian dan kondisi barang secara otomatis dan juga secara elektronik untuk memudahkan dalam pengelolaan laboratorium ke depan.

Hal ini dikarenakan semakin bertambahnya mahasiswa yang praktikum dan menggunakan peralatan dan komponen yang ada di laboratorium Teknik Elektro UBB, sehingga akan menyulitkan apabila masih menggunakan sistem pencatatan manual dan proses peminjaman dan lainnya juga dilakukan secara manual. Karena itu dibutuhkan sebuah aplikasi digital untuk menggantikan sistem manual ini

Beberapa tahapan dalam pembuatan aplikasi yaitu, identifikasi permasalahan, perancangan, pembuatan barcode dan tahap implementasi. Aplikasi dibuat menggunakan menggunakan software pengolah data, sedangkan barcode dibuat dengan software Barcode Studio. Pada tahapan perancangan dibuat database yang berisikan beberapa tabel-tabel database. Hasil dari penelitian ini telah diterapkan pada laboratorium Teknik Elektro dan sangat membantu dalam proses peminjaman, pengembalian, pengontrolan kondisi barang yang ada di laboratorium, dan pembuatan laporan.

Aplikasi ini berjalan offline dan artinya hanya bisa digunakan di komputer laboratorium Teknik Elektro UBB dan hanya hanya dapat digunakan oleh staf laboratorium untuk menjaga keamanan data dan akses yang terbatas sehingga data peralatan dan komponen laboratorium dapat menjadi lebih aman dan tersimpan dalam data elektronik bukan lagi manual dan dalam bentuk kertas sehingga mahasiswa hanya biasa mengajukan permohonan dan bisa mendapatkan peralatan dan komponen yang ingin digunakan setelah staff laboran menyetujui dan menggunakan sistem untuk mendata permintaan dari mahasiswa tersebut.

Kebanyakan sistem informasi inventaris laboratorium sudah berbasis internet dan berbeda dengan sistem inventaris yang berfokus untuk offline dan tidak menggunakan internet serta menggunakan barcode dan miocrosoft access sebagai database server.

\section{LANDASAN TEORI}

\section{A. Barcode}

Barcode atau kode batang pada dasarnya adalah susunan garis vertikal hitam dan putih dengan ketebalan yang berbeda, sangat sederhana tetapi sangat berguna, dengan kegunaan untuk menyimpan data-data spesifik misalnya kode produksi, tanggal kadaluwarsa, dan nomor identitas, teknologi barcode tersebut terus berkembang dan bertahan. Sedangkan untuk membaca barcode ada banyak pilihan di pasaran dengan harga yang relatif murah mulai dari yang berbentuk pena (wand), slot, dan scanner.

Barcode memiliki kelebihan-kelebihan tertentu, yang paling utama, murah dan mudah, sebab media yang digunakan adalah kertas dan tinta. Penggunaan barcode scanner juga sangat mudah. Barcode scanner dapat membaca informasi/data dengan kecepatan yang jauh lebih tinggi daripada mengetikkan data dan barcode scanner memiliki tingkat ketelitian yang lebih tinggi dalam melakukan pembacaan.

Sistem barcode ini pertama kali ditemukan oleh Wallace Flint untuk kebutuhan industri di perusahaannya yang bergerak di bidang ritail di Amerika. Temuan sederhananya itu kemudian dikembangkan oleh Bernard Silver dan Norman Joseph Woodland dalam bidang temuan jenis tinta yang mampu dibaca dengan cepat dan hemat oleh mesin pemindai.

Terdapat berbagai jenis sistem barcode, salah satunya adalah barcode dengan sistem code 128. Code 128 adalah barcode dengan kerapatan tinggi, dapat mengkodekan keseluruhan simbol ASCII (128 karakter) dalam luasan yang paling minim dibandingkan dengan barcode jenis lain, hal ini disebabkan karena code 128 menggunakan 4 ketebalan elemen (bar atau spasi) yang berbeda (jenis yang lain kebanyakan menggunakan 2 ketebalan elemen yang berbeda).

Setiap karakter pada code 128 dikodekan oleh 3 bar dan 3 spasi (atau 6 elemen) dengan ketebalan masing-masing elemen 1 sampai 4 kali ketebalan minimum (module), jika dihitung dengan satuan module maka tiap karakter code 128 terdiri dari 11 module kecuali untuk stop character yang terdiri dari 4 bar 3 spasi (13 module). 


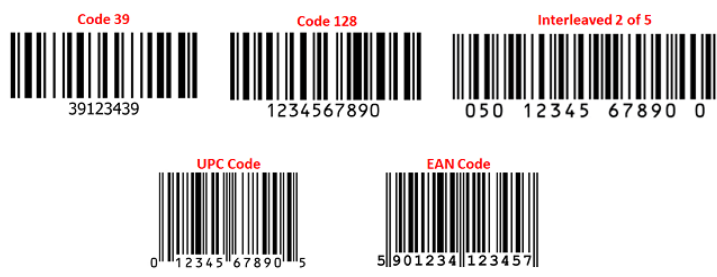

Gambar 1. Jenis-jenis Barcode 1D

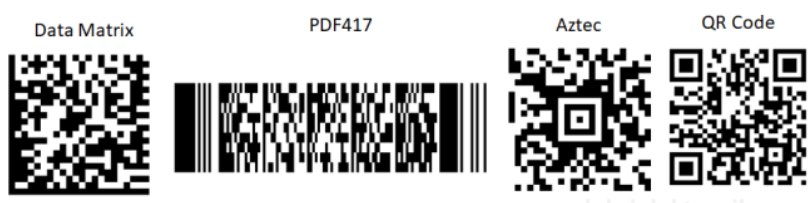

Gambar 2. Jenis-jenis Barcode 2D

\section{B. Software Pengolah Data}

Software Pengolah Data adalah sebuah program aplikasi basis data komputer relasional yang ditujukan untuk kalangan rumahan dan perusahaan kecil hingga menengah. Aplikasi ini menggunakan mesin basis data Microsoft Jet Database Engine dan juga menggunakan tampilan grafis yang intuitif sehingga memudahkan pengguna. Software Pengolah Data dapat menggunakan data yang disimpan di dalam format Access, Jet Database Engine, SQL Server, dan Oracle Database. Software ini juga mendukung teknik-teknik pemrograman berorientasi objek, tetapi tidak dapat digolongkan ke dalam perangkat bantu pemrograman berorientasi objek.

Terdapat enam obyek penting Access yang menjadi fitur utama, yaitu

1. Table. Tabel adalah tempat dimana kita menyimpan data. Semua tabel mengikuti aturan basis data relasional yang terdiri dari baris dan kolom. Setiap basis data bisa berisi lebih dari satu tabel.

2. Queries. Fitur queries disediakan untuk memilih data yang akan kita tampilkan. Queries pada Access disediakan baik dalam bentuk GUI maupun dalam bentuk bahasa SQL.

3. Forms. Fitur form disediakan untuk membuat tampilan dari basis data yang dibuat menjadi lebih menarik. Baik ketika mengedit data maupun tampilan output data di layar monitor.

4. Reports. Fitur ini disediakan untuk membuat format pencetakan pada media kertas melalui printer.
5. Macros. Fitur macro merupakan fitur yang digunakan untuk menyimpan perintah-perintah otomatis tertentu yang berhubungan dengan basis data yang dibuat. Dibutuhkan kemampuan pemrograman untuk menggunakan fasilitas ini.

6. Modules. Fitur ini lebih luas dari macro karena kita dapat melakukan pemrograman pada banyak aspek.

\section{METODE PENELITIAN}

Sebelum pembuatan aplikasi, harus diidentifikasi permasalahan dalam inventaris barang laboratorium sehingga aplikasi yang dibuat dapat benar benar menyelesaikan permasalahan yang ada. Hasil identifikasi digunakan untuk pembuatan aplikasi. Tahapan-tahapan yang dilakukan dalam penelitian diperlihatkan pada Gambar 3.

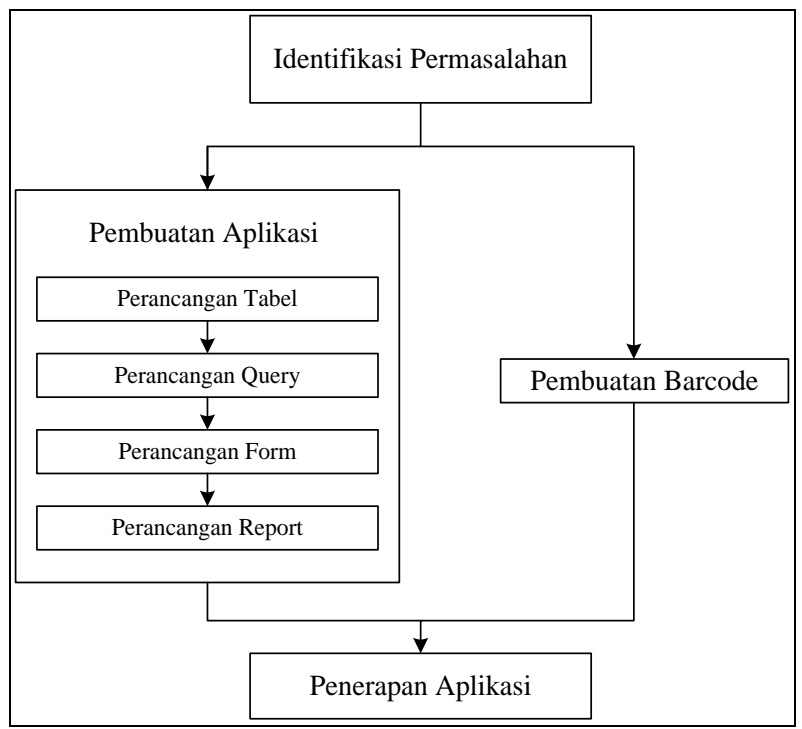

Gambar 3. Langkah Penelitian

Barcode yang dibuat digunakan untuk pengkodean barang dengan mengacu jumlah barang yang ada, yaitu sebanyak 719 buah. Barcode yang digunakan adalah linier barcode tipe code128 dengan 4 buah angka. Hasil cetak barcode ditempelkan pada setiap barang menggunakan kertas stiker. Contoh barcode untuk kode barang 719 diperlihatkan pada Gambar 4. 


\section{\|\|\|\|\|\|\|\|$\|||$}

Gambar 4. Barcode tipe code 128 untuk kode barang 719

Jumlah tabel yang digunakan pada Microsoft Access untuk pembuatan aplikasi sebanyak 4 tabel. Tabel barang, berisi data mengenai kode barang, identitas barang, tempat penyimpanan, ketersediaan barang (dipinjam/tersedia), jumlah pemakaian dan lama pemakaian. Tabel peminjaman berisi data identitas peminjam, kode barang yang dipinjam, dan waktu peminjaman. Tabel pengembalian berisi data kode barang, identitas peminjam, waktu pengembalian dan kondisi barang saat pengembalian. Tabel identitas berisi data mengenai identitas peminjam yaitu data mahasiswa dan dosen.

Hubungan tabel-tabel tersebut pada query diatur agar proses peminjaman, pengembalian, pengontrolan barang dan pembuatan laporan dapat dilakukan dengan mudah dan cepat serta dapat memberikan informasi yang diperlukan. Perancangan form dan report dibuat dengan mempertimbangkan kemudahan dalam proses memasukkan data dan dapat menyajikan informasiinformasi yang diperlukan. Agar aplikasi yang dibuat dapat diakses melalui jaringan komputer, pengaturan jaringan dilakukan agar lalu lintas data dapat berlangsung dengan lancar, yaitu dengan mengkoneksikan setiap komputer pada homegroup yang sama.

\section{HASIL PENELITIAN DAN PEMBAHASAN}

Hasil penelitian dan pembahasan adalah penyajian hasil utama secara objektif, tanpa interpretasi, dalam suatu susunan logis dan teratur menggunakan bahasa ilustratif (gambar dan tabel) dan teks. Hasil dan pembahasan seharusnya diorganisasikan dalam suatu seri tabel atau gambar secara berurutan untuk menyajikan temuan utama dalam susunan logis. Secara umum disuguhkan secara bertahap dalam tiga bagian: uraian temuan data dan informasi yang terkumpul, analisis sesuai dengan rancangan penelitian, dan penafsiran serta penjelasan sintesisnya. Sertakan data pendukung yang berupa tabel, grafik, gambar, atau alat bantu lain seperlunya untuk memperjelas dan mempersingkat uraian yang harus diberikan.

Gambar 5 memperlihatkan tampilan awal (switchboard) ketika aplikasi dijalankan. Form peminjaman, pengembalian dan pengubahan data dilindingi dengan password karena proses tersebut hanya boleh dilakukan oleh pengelola laboratorium.

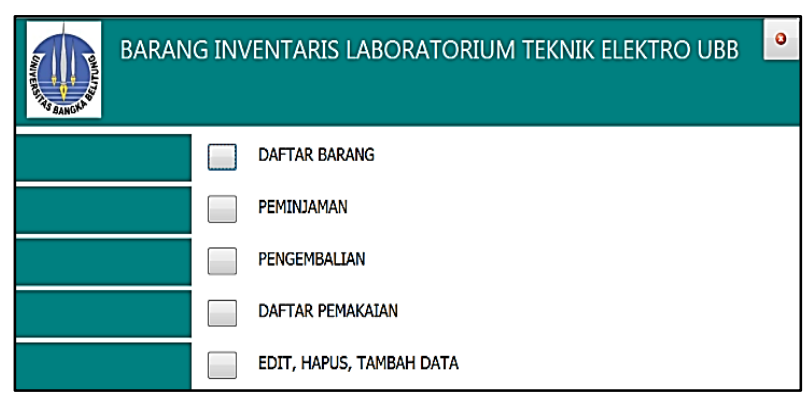

Gambar 5. Switchboard aplikasi

Form daftar barang inventaris berisi informasi mengenai indentitas barang, ketersediaan, banyaknya pemakaian dan lama pemakaian (Gambar 6). Form tersebut dilengkapi dengan tombol daftar peminjaman. Ketika tombol tersebut ditekan, maka akan diberikan informasi mengenai siapa saja yang telah menggunakan peralatan yang dipilih pada form daftar barang inventaris.

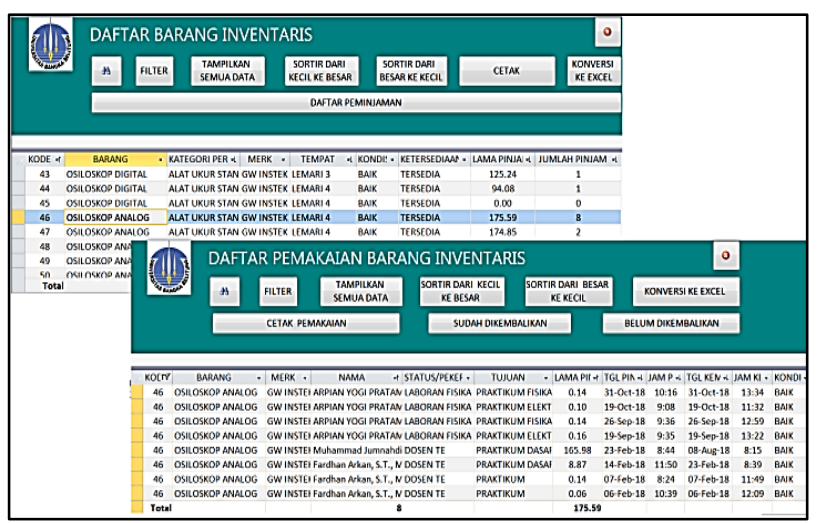

Gambar 6. Form daftar barang dan daftar pemakaian barang

Form daftar pemakaian barang memberikan informasi mengenai identitas pengguna barang dan lama peminjaman (Gambar 6). Jika suatu barang telah terpinjam selama lebih dari 14 hari dan peminjam hendak meminjam barang yang lain, maka aplikasi akan memberikan pesan kepada operator bahwa terdapat barang yang dipinjam lebih dari 14 hari dan belum dikembalikan (Gambar 8). Form tersebut juga dapat menampilkan informasi barang yang sudah dan 
Jurnal ECOTIPE, Vol. 8, No.1, April 2021, Hal. 33-38

p-ISSN 2355-5068, e-ISSN 2622-4852

Akreditasi Kemenristekdikti (SINTA 4), SK. No.10/E/KPT/2019

DOI: 10.33019/ecotipe.v8i1.1922

belum dikembalikan (Gambar 7). Untuk menampilkan seluruh data pemakaian barang dilakukan dengan tombol Tampilkan Semua Data.

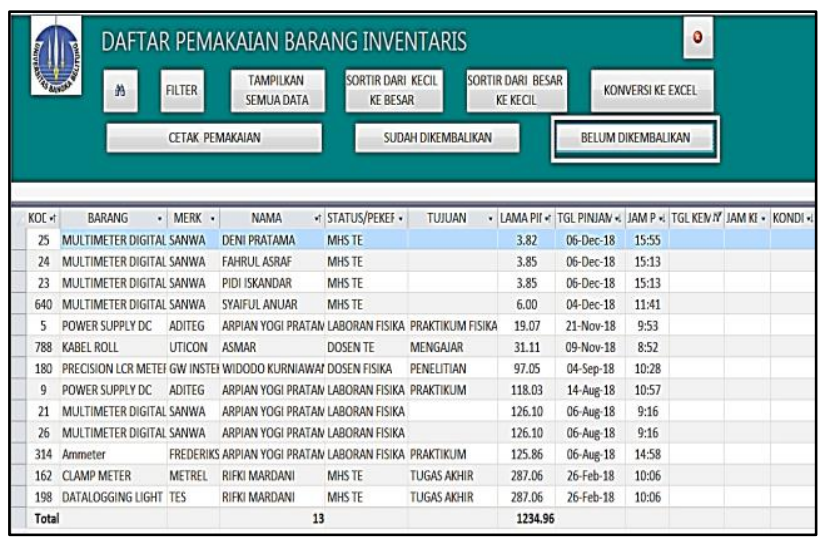

Gambar 7. Daftar pemakaian barang yang belum dikembalikan

Form untuk peminjaman diperlihatkan pada Gambar 8 dan 9. Untuk melakukan proses peminjaman barang, operator cukup memasukkan nomor identitas kemudian aplikasi akan mencari identitas lengkap peminjam pada tabel identitas. Sedangkan proses memasukkan data barang dilakukan dengan melakukan scanning menggunakan barcode reader pada barcode yang telah ditempelkan pada peralatan. Proses barcode sangat mudah karena perpindahan record akan selalu menuju ke field kode barang sehingga operator tidak perlu lagi menggunakan keyboard untuk menuju field kode barang.

Aplikasi juga memungkinkan untuk melakukan proses pembacaan barcode secara berulang. Pengulangan tersebut tidak akan diproses oleh aplikasi jika kode barang telah terbaca oleh aplikasi. Hal ini bertujuan untuk menghindari kesalahan operator terutama jika jumlah barang yang dipinjam memiliki jumlah yang relatif banyak sehingga operator dapat melakukan scanning ulang untuk memastikan bahwa data barang telah terinput.

Jika terdapat barang yang akan dibatalkan peminjamannya, operator cukup melakukan double click pada kode barang dan barang tersebut tidak akan terdata sebagai barang yang dipinjam (Gambar 9). Form peminjaman juga menyediakan tombol untuk membuka report formulir peminjaman yang telah terisi data yang lengkap dan hanya perlu ditandatangani.

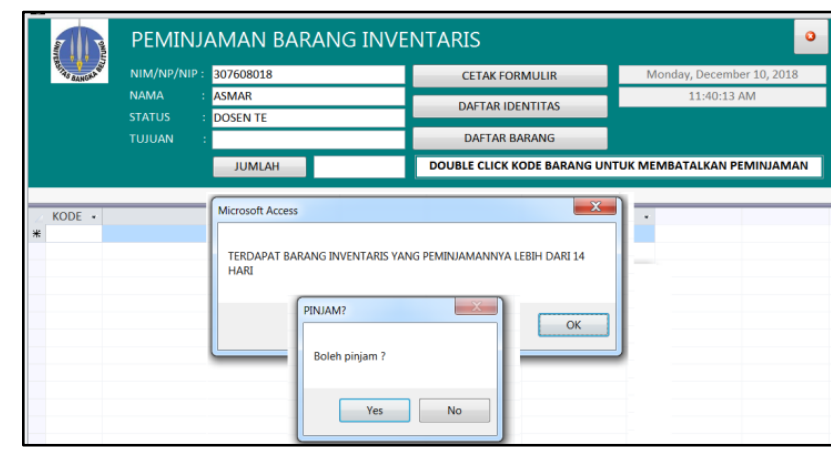

Gambar 8. Form peminjaman dan pesan yang ditampilkan jika terdapat barang yang dipinjam lebih dari 14 hari

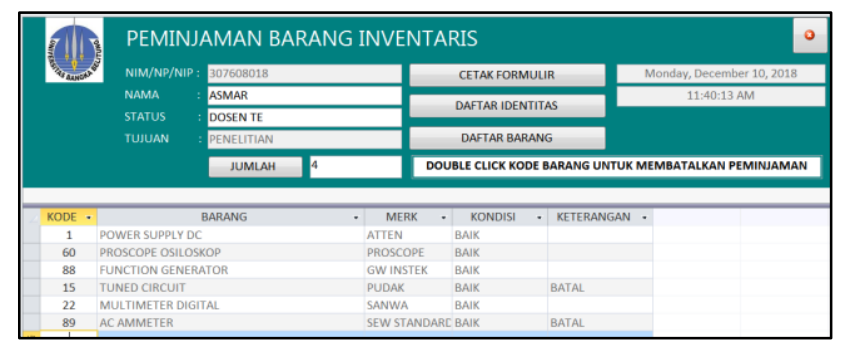

Gambar 9. Form peminjaman dan pembatalan peminjaman

Proses pengembalian juga dapat dilakukan dengan mudah pada Gambar 10. Operator cukup memasukan kode barang tanpa perlu mancari identitas peminjam. Hal ini dapat dilakukan karena form pengembalian diatur pada mode add. Mode add ini memungkinkan karena peminjaman dan pengembalian masing-masing menggunakan tabel yang terpisah. Jika peminjaman dan pengembalian digabung menjadi satu tabel, maka proses pengembalian harus dalam mode edit, hal ini kurang efieien karena selain kode barang, operator juga harus mengetahui atau mencari data peminjam.

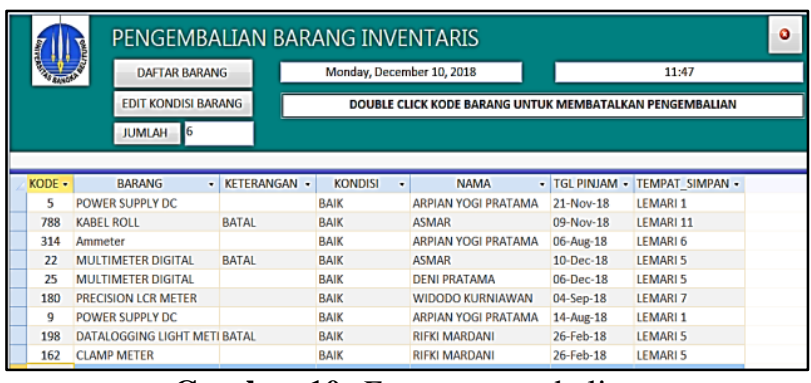

Gambar 10. Form pengembalian

Aplikasi yang dibuat dapat menghasilkan 3 jenis laporan (report), yaitu kondisi barang, formulir peminjaman, dan daftar pemakaian barang. Contoh report untuk formulir peminjaman diperlihatkan pada Gambar 11. Form-form pada aplikasi juga dilengkapi 
tombol-tombol untuk memudahkan operator dalam memperoleh informasi yaitu tombol untuk mencari data, menyaring data, mengurutkan data, dan mencetak laporan. Aplikasi juga memungkinkan untuk melakukan konversi data menjadi file excel sehingga operator dapat membuat laporan dan mengolah data dalam format excel.

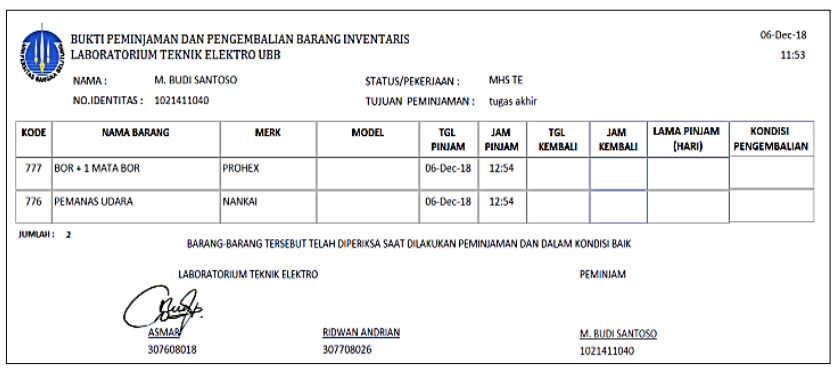

Gambar 11. Report untuk formulir peminjaman

Agar aplikasi dapat diakses melalui jaringan, maka setiap komputer diatur dalam satu homegroup yang sama dan folder tempat aplikasi tersebut berada harus dibagikan (shared)ke komputer lain. Aplikasi tersebut juga dapat diakses lebih dari satu komputer secara bersamaan dan proses perekaman dan penampilan data tetap dapat berlangsung dengan baik.

\section{KESIMPULAN}

Aplikasi invetarisasi ini telah diterapkan pada laboratorium Teknik Elektro dan membantu dalam proses peminjaman, pengembalian, pengontrolan kondisi barang, dan pembuatan laporan secara lebih mudah dan elektronik dan mampu menggantikan sistem yang manual dan menggunakan kertas.

Aplikasi yang dihasilkan dikembangkan untuk menginventaris barang habis pakai (barang pesediaan) yang terintegrasi dengan barang inventaris sehingga mempunyai fitur yang lebih lengkap dan memberikan kemudahan bagi staf laboratorium dalam mengelola invetarisasi laboratorium.

\section{REFERENSI}

[1]. Jogiyanto, 2005, Analisis dan Disain Sistem Informasi Pendekatan Terstruktur Teori dan Praktek Aplikasi Bisnis, Cetakan Ketiga, Andi, Yogyakarta.

[2]. David M. Kroenke, 2002, Database Processing Fundamentals, Design, and Implementation, Eight Edition, Pretince Hall.
[3]. Madcoms ， 2015, Membangun aplikasi stok inventori, Andi Publisher

[4]. Kukuh Nugroho, 2016, Jaringan Komputer, Media Tera

[5]. Barcode, http://en.wikipedia.org.

[6]. Data Net: Barcode Primer, http://www.datanet.com/education/barcodes.html

[7]. "Sistem Informasi Inventaris Laboratorium Berbasis Web Pada Stikes Bhakti Mandala Husada Slawi" Aghafiana Dewi Maharani, Slamet Wiyono, 2016, Jurnal Informatika

[8]. Perancangan Sistem Informasi Invetarisasi Labotorium Berbasis Web, Hardini Ratna Puspitawati, Heru Wahyu Herwanto, Jurnal Tekno, 2012, Vol.17

[9]. Perancangan Sistem Informasi Invetarisasi Labotorium Berbasis Web, Hardini Ratna Puspitawati, Heru Wahyu Herwanto, Jurnal Tekno, 2012, Vol.17

[10]. "Perancangan Sistem Informasi Laboratorium Komputer Pada Program Studi D III PMIK Poltekes Kemenkes Malang", Puguh Yudho Trisnato, Handy Lala, Vol 1, No.11, 2016 